\title{
The Effect of Neutron Irradiation on Silicon Carbide Fibers
}

$$
\text { CONF-970111-- }
$$

\author{
G. A. Newsome
}

January 1997

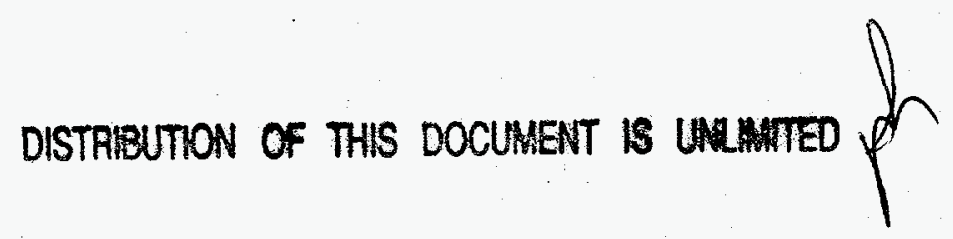

\section{NOTICE}

This report was prepared as an account of work sponsored by the United States Government. Neither the United States, nor the United States Department of Energy, nor any of their employees, nor any of their contractors, subcontractors, or their employees, makes any warranty, express or implied, or assumes any legal liability or responsibility for the accuracy, completeness or usefulness of any information, apparatus, product or process disclosed, or represents that its use would not infringe privately owned rights.

Operated for the U. S. Department of Energy by KAPL, Inc. a Lockheed Martin company 


\section{DISCLAIMER}

This report was prepared as an account of work sponsored by an agency of the United States Government. Neither the United States Government nor any agency thereof, nor any of their employees, make any warranty, express or implied, or assumes any legal liability or responsibility for the accuracy, completeness, or usefulness of any information, apparatus, product, or process disclosed, or represents that its use would not infringe privately owned rights. Reference herein to any specific commercial product, process, or service by trade name, trademark, manufacturer, or otherwise does not necessarily constitute or imply its endorsement, recommendation, or favoring by the United States Government or any agency thereof. The views and opinions of authors expressed herein do not necessarily state or reflect those of the United States Government or any agency thereof. 


\section{DISCLAIMER}

\section{Portions of this document may be illegible in electronic image products. Images are produced from the best available original document.}




\title{
THE EFFECT OF NEUTRON IRRADIATION ON SILICON CARBIDE FIBERS
}

\author{
G.A. Newsome \\ Lockheed Martin, Schenectady, New York
}

\begin{abstract}
Nine types of SiC fiber have been exposed to neutron radiation in the Advanced Test Reactor at $250^{\circ} \mathrm{C}$ for various lengths of time ranging from 83 to 128 days. The effects of these exposures have been initially determined using scanning electron microscopy. The fibers tested were Nicalon ${ }^{\mathrm{TM}}$ CG, Tyranno, Hi-Nicalon' ${ }^{\mathrm{TM}}$, Dow Corning SiC, Carborundum SiC, Textron SCS-6, polymethysilane (PMS) derived SiC from the University of Michigan, and two types of MER SiC fiber. This covers a range of fibers from widely used commercial fibers to developmental fibers. Consistent with previous radiation experiments, Nicalon fiber was severely degraded by the neutron irradiation. Similarly, Tyranno suffered severe degradation. The more advanced fibers which approach the composition and properties of $\mathrm{SiC}$ performed well under irradiation. Of these, the Carborundum SiC fiber appeared to perform the best. The Hi-Nicalon and Dow Corning fibers exhibited good general stability, but also appear to have some surface roughening. The MER fibers and the Textron SCS-6 fibers both had carbon cores which adversely influenced the overall stability of the fibers.
\end{abstract}

\section{INTRODUCTION}

The objective of this study is to provide initial information on the radiation stability of silicon carbide fibers. Ceramic matrix composites made with these fibers are being investigated. Other studies have been reported on these and similar fibers and composites which showed that some SiC fibers shrink and debond from the matrix when irradiated. ${ }^{1,2}$ The debonding degrades the mechanical properties of the composite. Furthermore, crystalline $\mathrm{SiC}$ swells when irradiated which also promotes debonding. The scope of the current study is to confirm the behavior of the materials that have been previously tested and extend the database to newly developed and less well characterized fibers.

\section{MATERIALS AND EXPERIMENTAL PROCEDURE}

Table I lists the fibers evaluated in this study and some of their attributes. ${ }^{3-9}$ They include commercial fibers such as Nicalon $^{\mathrm{TM}}$, Tyranno, Hi-Nicalon ${ }^{\mathrm{TM}}$, and Textron SCS-6 as well as developmental fibers such as Dow Corning Crystalline SiC, Carborundum Sintered SiC, University of Michigan PMS-SiC, and MER SiC. The density and an estimate of the level of crystallinity of each of these fibers is also given in Table $\mathrm{I}$.

\section{Irradiation Conditions}

The fibers were irradiated in the Advanced Test Reactor in Idaho in an inert atmosphere at an irradiation temperature of about $250^{\circ} \mathrm{C}$. The reactor exposures ranged from 83 to 128 effective full power days (EFPD) which produced neutron fluences from 12.8 to $34.3 \times 10^{20} \mathrm{n} / \mathrm{cm}^{2}$ 
(E>0.1 MeV). This can be converted to a dose range of 1.0 to 2.8 displacements per atom SiC (dpa-SiC). Table II gives the radiation dose for each type of fiber tested. During the exposure, the fibers were sealed in an irradiation capsule that was filled with inert gas (helium or argon).

\section{Characterization}

The fibers were observed visually after they were removed from the irradiation capsule. This provided general insight into how the fibers performed. Many poor performing fibers crumbled into powder. High magnification scanning electron microscopy (SEM) was used to qualitatively assess the fibers. Particular attention was paid to changes in surface condition and to the ends of the fibers. Also, any characteristic features due to processing were investigated.

\section{RESULTS AND DISCUSSION}

The Nicalon ${ }^{\mathrm{TM}}$ fiber exhibited severe degradation due to irradiation (Figure 1). The fiber surface became very rough. This was consistent with the earlier studies of the irradiation performance of this fiber. However, it should be pointed out that the degree of damage seen here was much higher than previously reported. ${ }^{1,2}$ This may be a function of the low irradiation temperature of this test. Low temperature irradiation is more damaging than intermediate temperature irradiation $\left(1000-1200^{\circ} \mathrm{C}\right)$ since less damage is annealed out. The amorphous structure of this fiber is believed to be the reason for the poor performance. Further, the appearance of the irradiated fibers is similar to that of Nicalon ${ }^{\mathrm{TM}}$ fiber that has been degraded by thermal exposure (at temperatures greater than $1100^{\circ} \mathrm{C}$ ). These and earlier results clearly show that ceramic grade Nicalon ${ }^{\mathrm{TM}}$ is not suitable for applications that require neutron irradiation. Table II summarizes the effect of irradiation observed in this test.

The Tyranno fiber displayed the most degradation of all the fibers tested here (Figure 2). This fiber disintegrated into mostly powder with only small fragments of fiber remaining. In Figure 2 sections of the outer parts of the fiber that have not spalled off can be seen. This fiber is also highly amorphous (nearly $100 \%$ ) which causes the poor performance.

The Hi-Nicalon ${ }^{\mathrm{TM}}$ fiber showed only minor surface changes after the irradiation (Figure 3). The fiber appeared to have a rougher surface. This could cause a reduction in strength of the fiber and could limit the amount of fiber pull-out in a ceramic matrix composite. However, the fiber appeared to be acceptable for radiation environments. The changes in surface character may also be different if the fiber was coated or in a composite matrix.

The crystalline SiC fiber from Dow Corning exhibited some surface roughening (Figure 4) with more open porosity present. The boron sintering aid may have caused the increased porosity due to helium gas formation during irradiation.

The PMS-SiC fiber made by the University of Michigan had some minor damage after irradiation that appeared as crumbling or spalling of an outer surface layer (Figure 5). This had the effect of producing a somewhat rougher surface. The most interesting feature of this fiber was the rows of porosity that were visible after irradiation (Figure 5 and 6). The linear nature indicated that the distribution of whatever caused the porosity was controlled by the extrusion process used 
to make the fiber. There are several explanations for the linear porosity including entrapped gas during the fiber forming process and helium gas generation during irradiation from clumped boron.

The sintered SiC fiber from Carborundum showed the least amount of degradation (change) with irradiation. The major change was that the surface became smoother (Figure 7). This was the opposite response to what happened to most of the other fibers. This could lead to higher fiber strengths and higher pull-out amounts for composites made with this fiber. This fiber also had a small amount of boron, but no evidence of increased porosity due to helium gas generation was evident. The amount of boron in this fiber was probably much less than that in the other fibers.

The MER SiC fibers underwent some surface roughening during irradiation. For the fiber produced from the T300 carbon fiber, the striated surface roughness transformed into general surface roughness (Figure 8). Furthermore, most of the longitudinal cracks present prior to irradiation disappeared. This fiber also appeared to have a multi-layer internal structure. At the ends of the individual filaments, the outer portion of this fiber had spalled away (Figure 9). The MER fiber produced from the IM9 carbon fiber went from a relatively smooth surface to a rough surface with irradiation (Figure 10). As with the other MER fiber, the cracks present prior to irradiation were not present after irradiation.

The Textron SCS-6 fiber had an interesting response to the irradiation due to its structure. The carbon filament which serves as a mandrel during the chemical vapor deposition (CVD) processing of this fiber shrank away from the SiC part of the fiber due to the irradiation (Figure 11). The shrinkage of the carbon filament was consistent with the behavior of irradiated graphite. ${ }^{10}$ Similarly, the carbon rich coating on the SCS-6 fiber also degraded (Figure 12). It appeared to peel off in some locations and to spall locally in others. The SiC portion of this fiber, however, appeared to be unaffected. The shrinkage of the carbon core of the SCS-6 fiber does not preclude the use of this or any other similar fiber in composites intended for neutron exposure. However, at high neutron exposures and irradiation temperatures, carbon will stop shrinking and start to expand. If this expansion is such that it causes the carbon core to push on the $\mathrm{SiC}$ portion of the fiber, mechanical degradation of the fiber may occur.

The significantly amorphous polymer derived fibers (Nicalon ${ }^{\mathrm{TM}}$ and Tyranno) were severely degraded by irradiation such that they would not be suitable for neutron radiation environments. Fibers that are primarily crystalline $\mathrm{SiC}$ and have only minor amounts of boron (HiNicalon ${ }^{\mathrm{TM}}$ and Sintered SiC from Carborundum) had the best performance under irradiation. These two fibers had only small changes in surface appearance. Polymer derived fibers with larger amounts of boron (Dow Corning Crystalline SiC and PMS-SiC) had major changes in surface appearance and an increase in surface porosity. This can be addressed by either a reduction in the boron content or by changing the isotopic enrichment of the boron such that less helium is generated. The MER SiC fibers held together rather well, except for the increase in surface roughness. Finally, the SiC portion of Textron SCS-6 fiber showed good stability, but the carbon core and carbon rich outer coating were degraded. The shrinkage of the carbon core in itself may not be detrimental to the performance of the SCS- 6 fiber. 


\section{SUMMARY}

Several SiC fibers were irradiation tested to gage their performance under neutron irradiation. Fibers which were significantly amorphous were severely degraded by the radiation. Fibers that approach crystalline SiC showed only small changes, primarily in the texture of the surface. Two fibers appeared acceptable as they exist today, while several others will require more development before they are acceptable for neutron radiation environments.

\section{ACKNOWLEDGEMENTS}

The efforts of Rick Jones and Dan Petrak of Dow Corning, Chris Ebel of Carborundum, Witold Kowbel of MER, Rick Laine of the University of Michigan, and John Letko, Firm Weaver, and John Woods of Lockheed Martin in providing fiber samples for this test is greatly appreciated.

\section{REFERENCES}

1. G.W. Hollenberg, C.H. Henager, Jr., G.E. Youngblood, D.J. Trimble, S.A. Simonson, G.A. Newsome, and E. Lewis, "The Effect of Irradiation on the Stability and Properties of Monolithic Silicon Carbide and SiC/SiC Composites up to $25 \mathrm{dpa,"} \mathrm{J.} \mathrm{Nucl.} \mathrm{Mater.,} \mathrm{219,}$ 70, 1995.

2. L.L. Snead, M. Osborne, K.L. More, "Effects of Radiation on SiC-based Nicalon Fibers," J. Mater. Res. 10 [3] 736-747, 1995

3. J. Lipowitz, J.A. Rabe, K.T. Nguyen, L.D. Or, and R.R. Androl, "Structure and Properties of Polymer-Derived Stoichiometric SiC Fiber," Ceram. Eng. Sci. Proc., 16, [4] 55-62, 1995.

4. R.M. Laine, Z.F. Zhang, K.W. Chew, M. Kannisto, and C. Scotto, "Silicon Carbide Fibers, Synthesis and Processing," Ceram. Eng. Sci. Proc. 15 [4] 152-161, 1994.

5. M. Takeda, J. Sakamoto, A. Saeki, Y. Imai, H. Ichikawa, "High Performance Silicon Carbide Fiber Hi-Nicalon for Ceramic-matrix Composites," Ceram. Eng. Sci. Proc. 16 [4] 37-44, 1995.

6. F. Frechette, B. Dover, V. Venkāteswaran, and J.J. Kim, "High Temperature Sintered SiC Fibers for Composite Applications," Ceram. Eng. Sci. Proc. 12 [7-8] 992-1006, 1991.

7. X.J. Ning and P. Pirouz, "The Microstructure of SCS-6 SiC Fiber," J. Mater. Res. 6 [10] 2234$2248,1991$.

8. J.K. Weddell, "Continuous Ceramic Fibres," J. Text. Inst. 81 [4] 333-359, 1990.

9. T.F. Cooke, "Inorganic Fibers - A Literature Review," J. Am. Ceram. Soc. 74 [12] 2959-2978, 1991. 
10. T.D. Burchell and W.P. Eatherly, "The Effects of Radiation Damage on the Properties of Graphnol N3M," J. Nucl. Mater. 34-36, 205-208, 199.

TABLE I - Manufacturer and Key Attributes of Tested Fibers ${ }^{3-9}$

\begin{tabular}{|c|c|c|c|c|c|}
\hline Fiber & Vendor & $\begin{array}{l}\text { Year } \\
\text { Made }\end{array}$ & $\begin{array}{l}\text { Composition } \\
(w t \%)\end{array}$ & $\begin{array}{l}\text { Density } \\
\left(\mathrm{g} / \mathrm{cm}^{3}\right)\end{array}$ & $\begin{array}{c}\text { Crystallinity* } \\
\%\end{array}$ \\
\hline Nicalon $^{\mathrm{TM}} \mathrm{CG}$ & Nippon & 1993 & Si-31C-12O & 2.55 & 44 \\
\hline Tyranno & Ube & 1993 & Si-28C-17O-3Ti & 2.37 & $\mathbf{0}$ \\
\hline Hi-Nicalon ${ }^{\mathrm{TM}}$ & Nippon & 1993 & Si-36C-0.5O & 2.74 & 90 \\
\hline SCS-6 & Textron & 1993 & $\mathrm{SiC}+\mathrm{C}$ & 3.2 & 100 \\
\hline Crystalline SiC & Dow Corning & 1994 & Si-28C-2.3B- 0.90 & 3.0 & 95 \\
\hline Sintered SiC & Carborundum & 1994 & $\mathrm{SiC}+\mathrm{B}$ & 3.15 & 100 \\
\hline PMS-SiC & U. of Michigan & 1993 & $\mathrm{Si}-31 \mathrm{C}+\mathrm{B}$ & 3.1 & 90 \\
\hline MER SiC (T300) & MER & 1994 & Si-30C & 3.1 & 100 \\
\hline MER SiC (IM9) & MER & 1994 & $\mathrm{Si}-30 \mathrm{C}$ & 31 & 100 \\
\hline
\end{tabular}

* Crystallinity is estimated from $\mathrm{x}$-ray diffraction and density data.

TABLE II - Summary of the Effect of Neutron Irradiation

\begin{tabular}{|c|c|c|c|}
\hline Fiber & $\frac{\text { Dose }}{\text { dpa-SiC }}$ & Observations & $\begin{array}{l}\text { Acceptable for } \\
\text { Radiation Env. }\end{array}$ \\
\hline Nicalon $^{\mathrm{TM}}$ CG & 2.5 & major degradation & no \\
\hline Tyranno & 2.4 & major degradation, worst & no \\
\hline Hi-Nicalon $^{\mathrm{TM}}$ & 2.8 & minor surface changes & yes \\
\hline Crystalline SiC & 2.0 & some surface degradation & marginal \\
\hline PMS-SiC & 1.8 & some surface degradation & marginal \\
\hline Sintered SiC & 2.0 & good performance, surface smoothing & yes \\
\hline MER SiC (T300) & 1.0 & increase in surface roughness & marginal \\
\hline MER SiC (IM9) & 2.4 & increase in surface roughness & marginal \\
\hline SCS-6 & 2.0 & $\begin{array}{l}\text { shrinkage of carbon core } \\
\text { degradation of carbon rich surface layer } \\
\text { no observed changes to } \mathrm{SiC} \text { portion }\end{array}$ & marginal \\
\hline
\end{tabular}




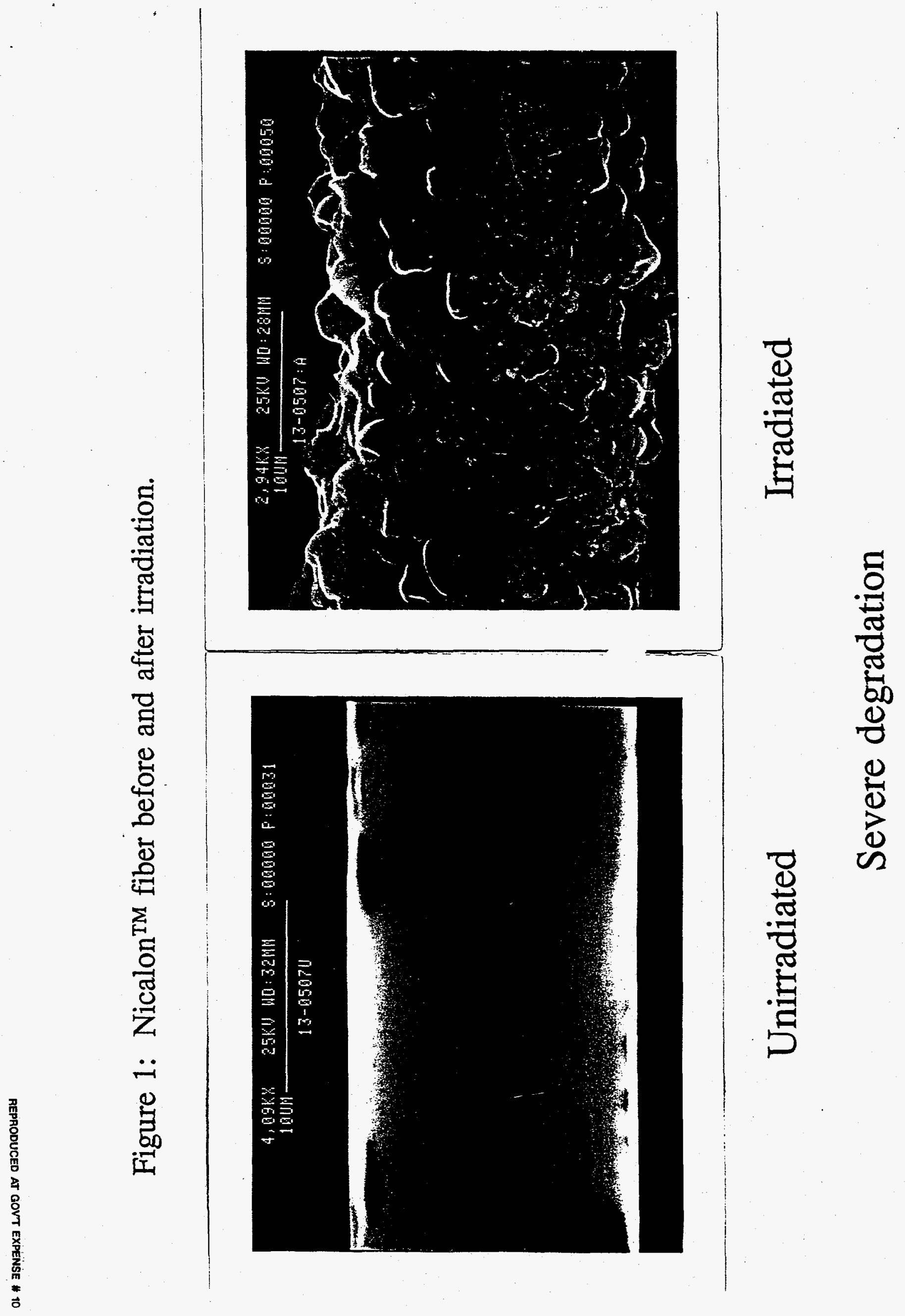


Figure 2: Tyranno fiber before and after irradiation.
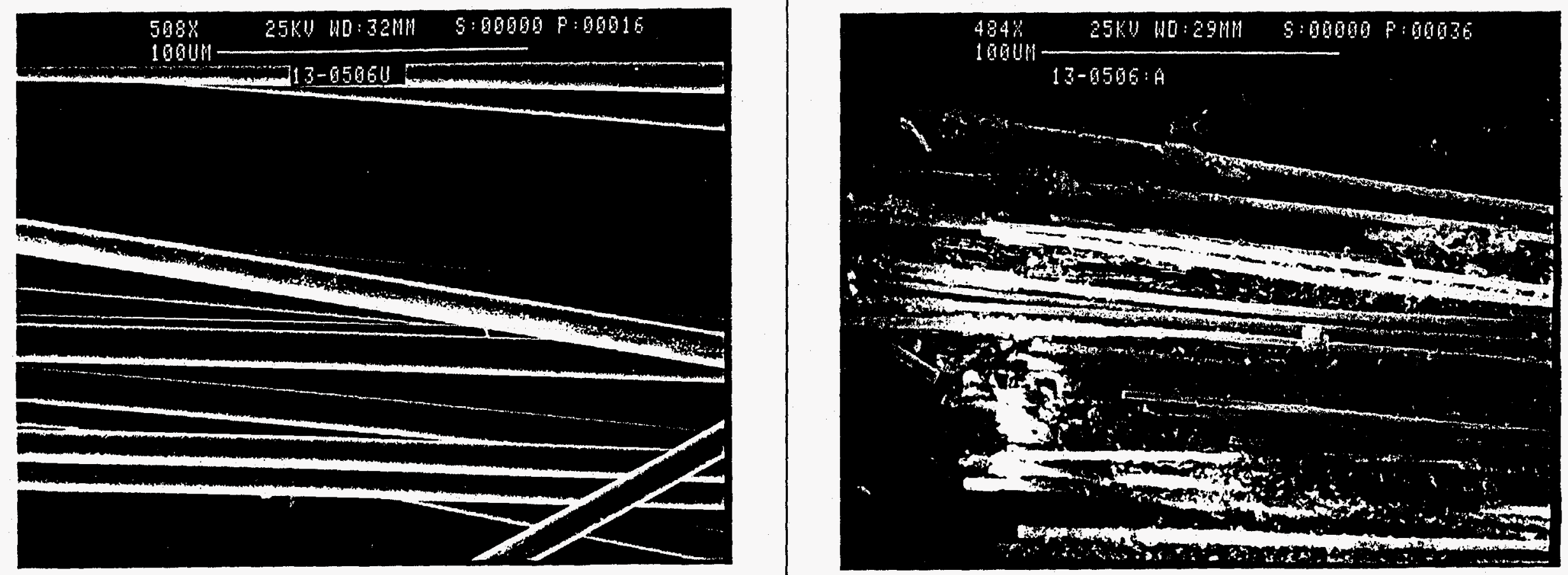

Unirradiated

Irradiated

Severe Degradation - outer portions of the fiber crumble off 
Figure 3: Hi-Nicalon ${ }^{\mathrm{TM}}$ fiber before and after irradiation.
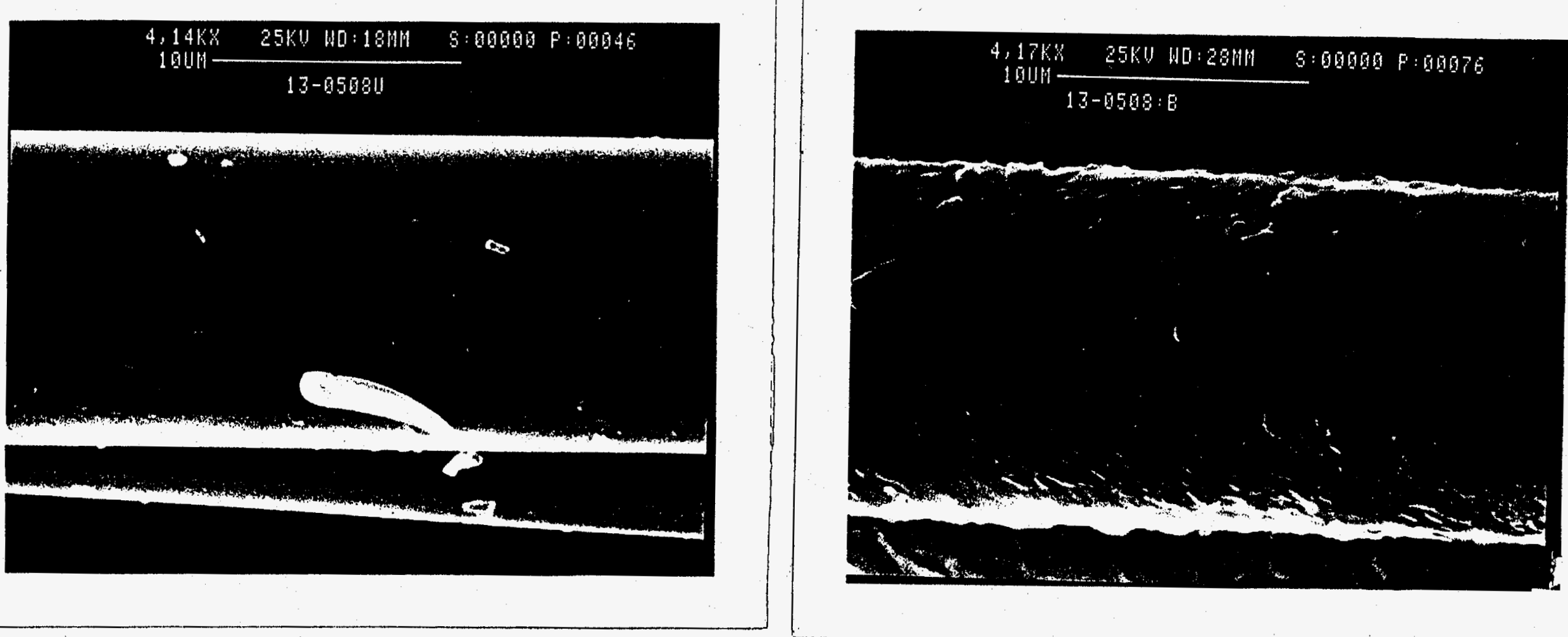

Unirradiated

Irradiated

Minimal Degradation - some surface roughening 
Figure 4: Dow Corning Crystalline SiC fiber before and after irradiation.
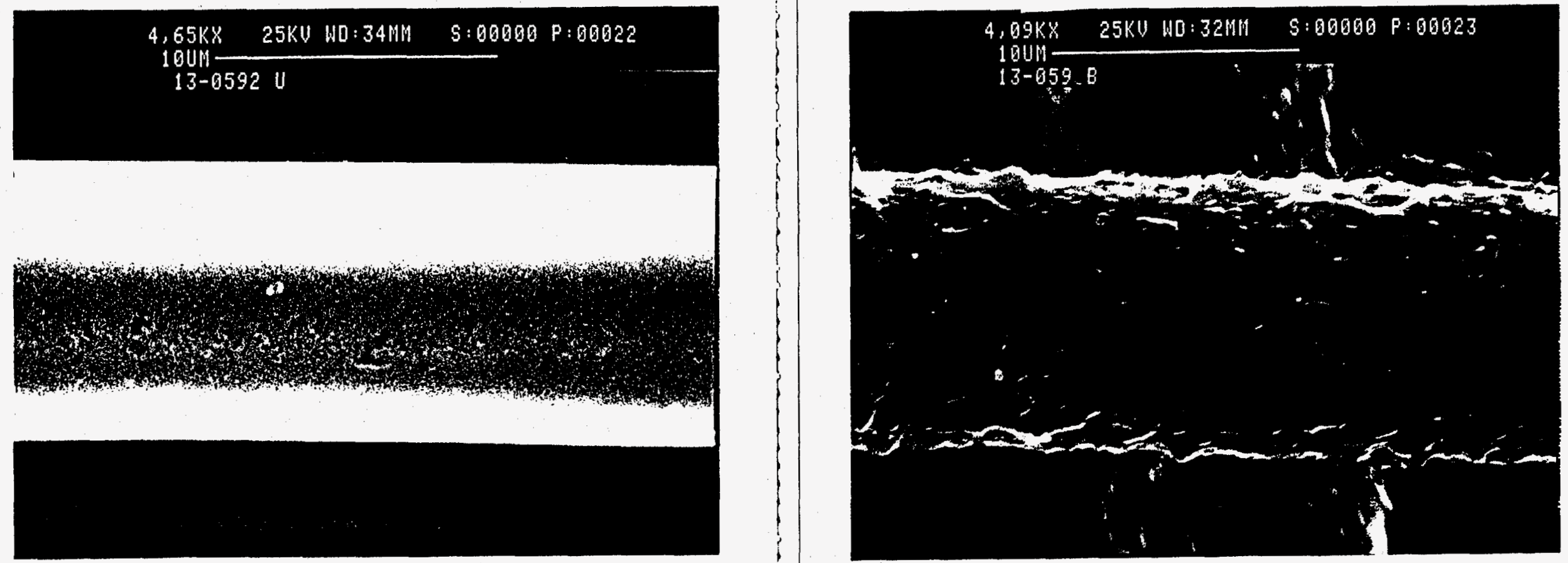

Unirradiated

Irradiated

Some Degradation - surface roughening, more porosity 
Figure 5: University of Michigan PMS-SiC fiber before and after irradiation.

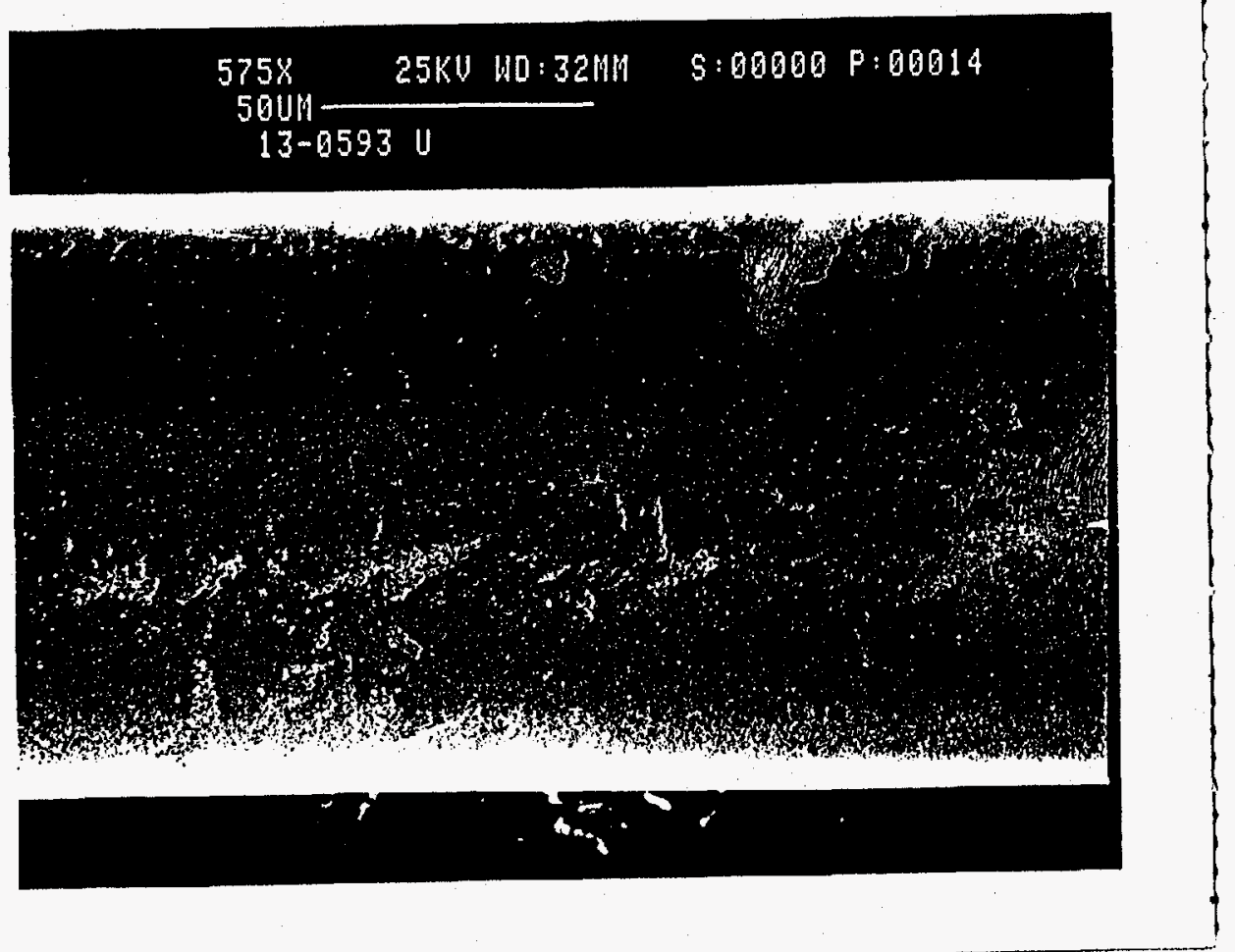

Unirradiated

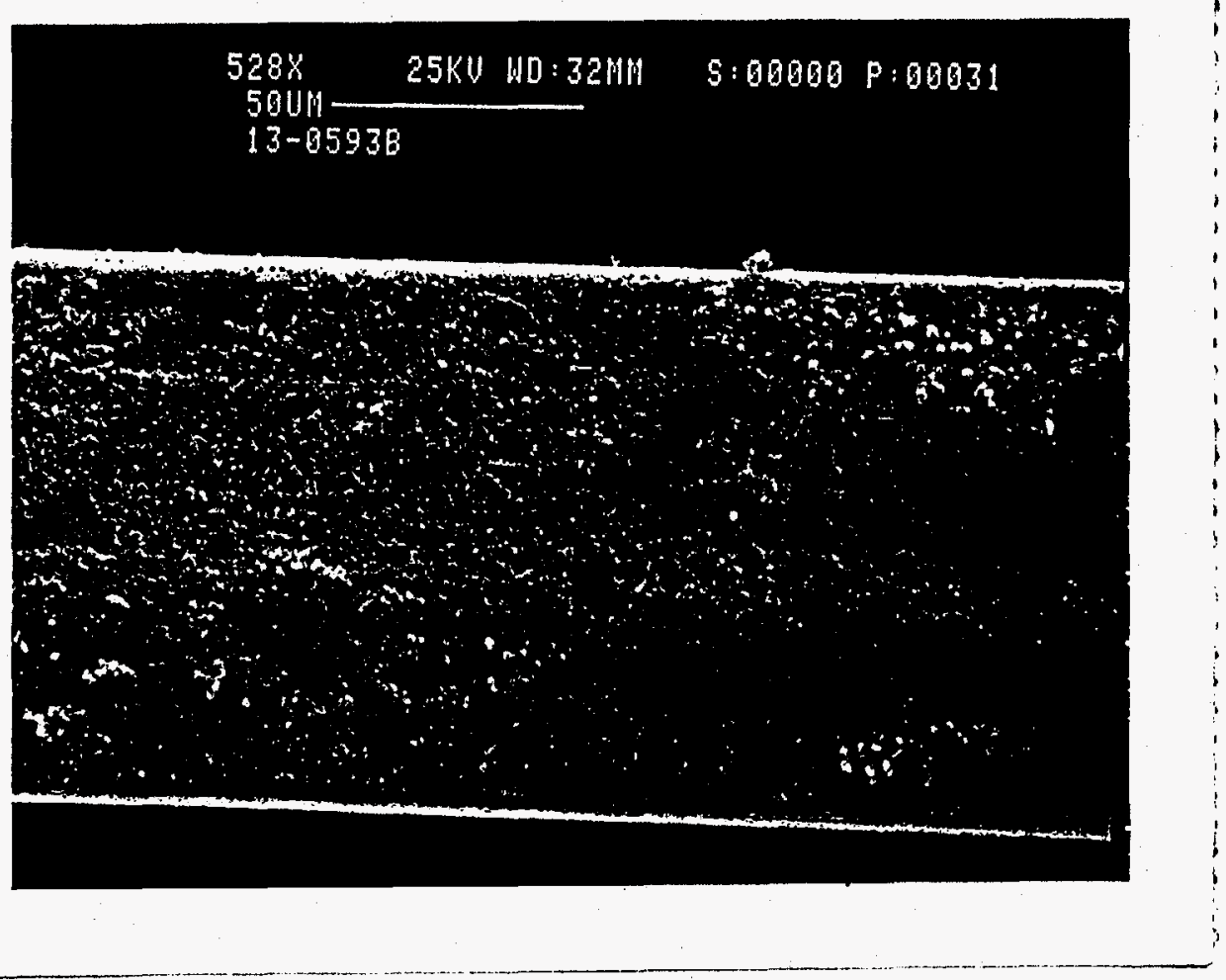

Irradiated

Surface degradation - surface layer crumbled, rows of porosity 
Figure 6: Close-up of row of porosity found on PMS-SiC fiber after irradiation.

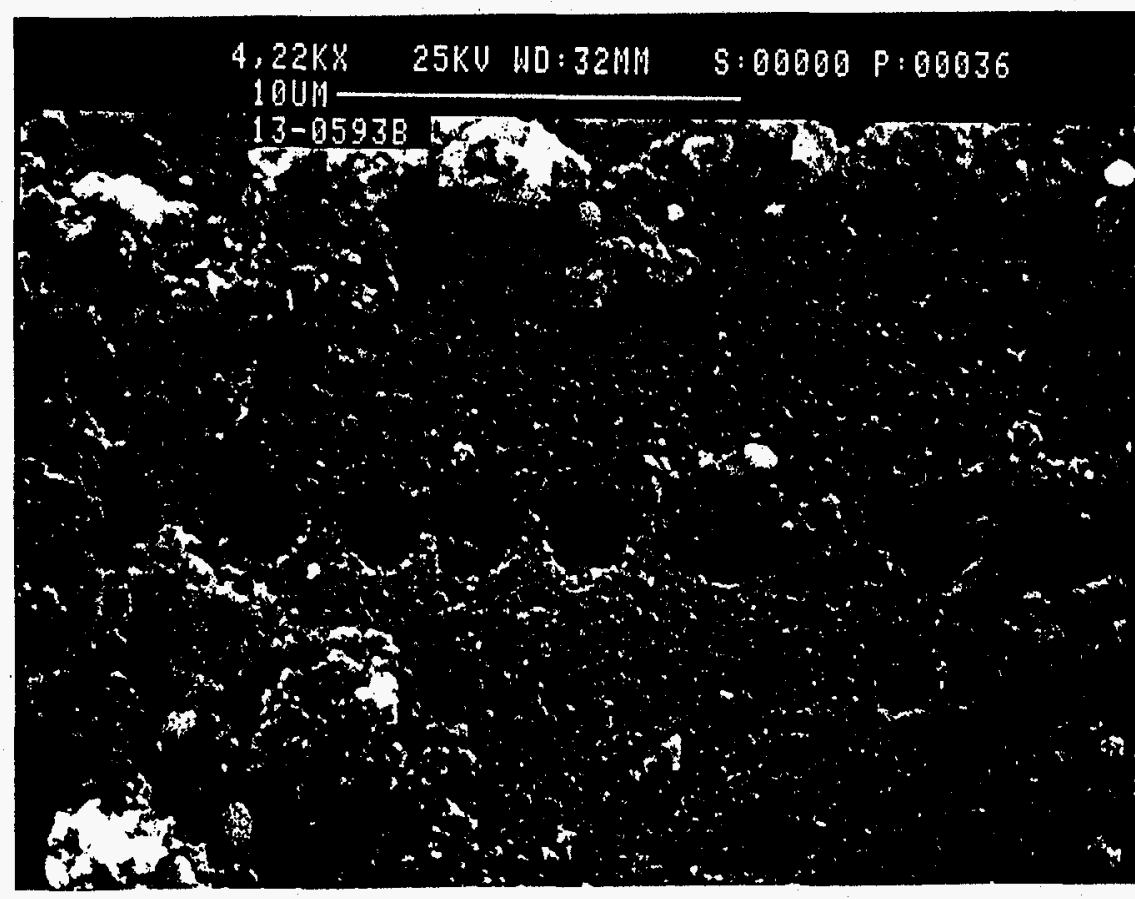

\section{Irradiated}

Surface degradation - row of porosity 
Figure 7: Carborundum Sintered SiC fiber before and after irradiation.
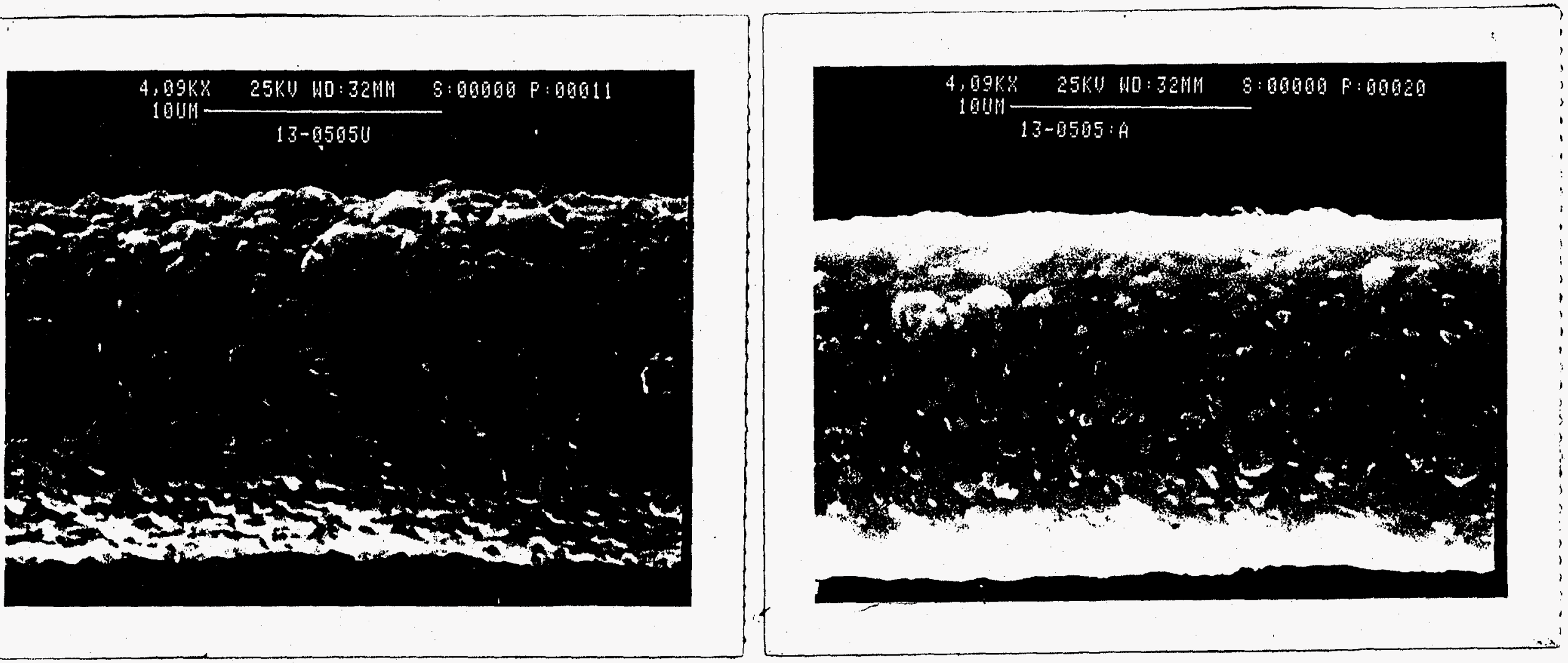

Unirradiated

Irradiated

Minimal Degradation - smoother surface 
Figure 8: MER SiC (T300) fiber before and after irradiation.
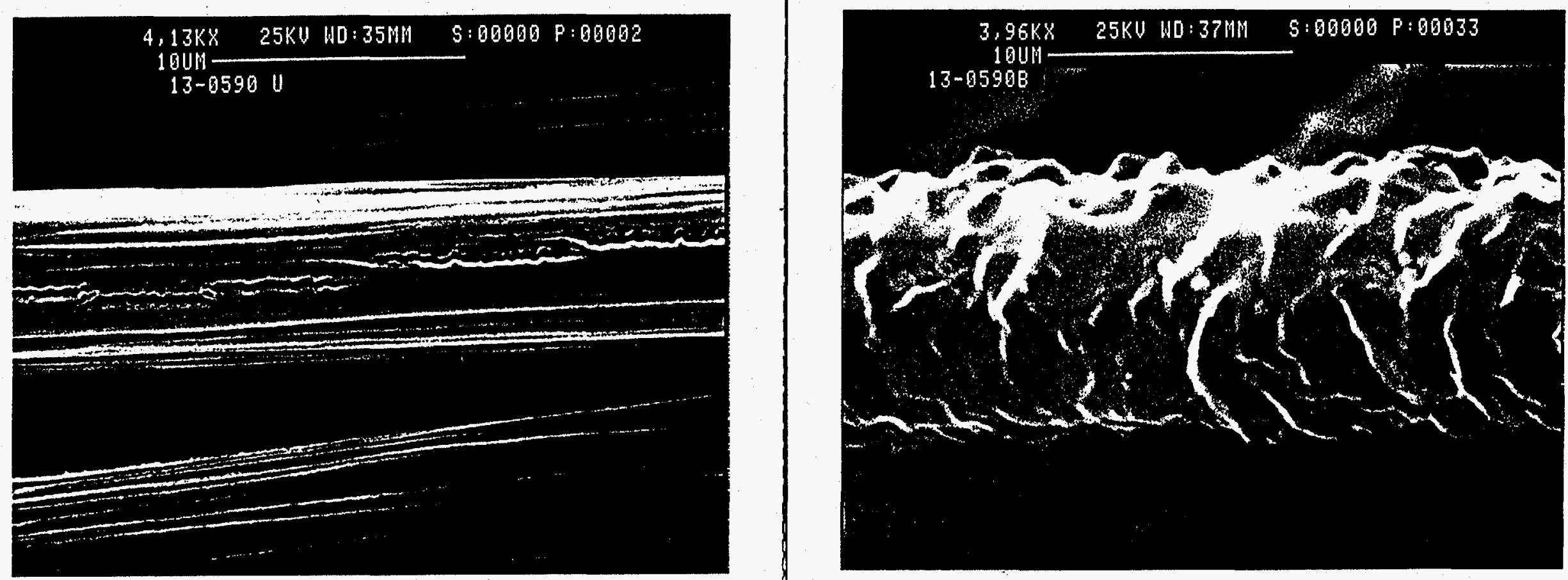

Unirradiated

Irradiated

Change in type of surface roughness 


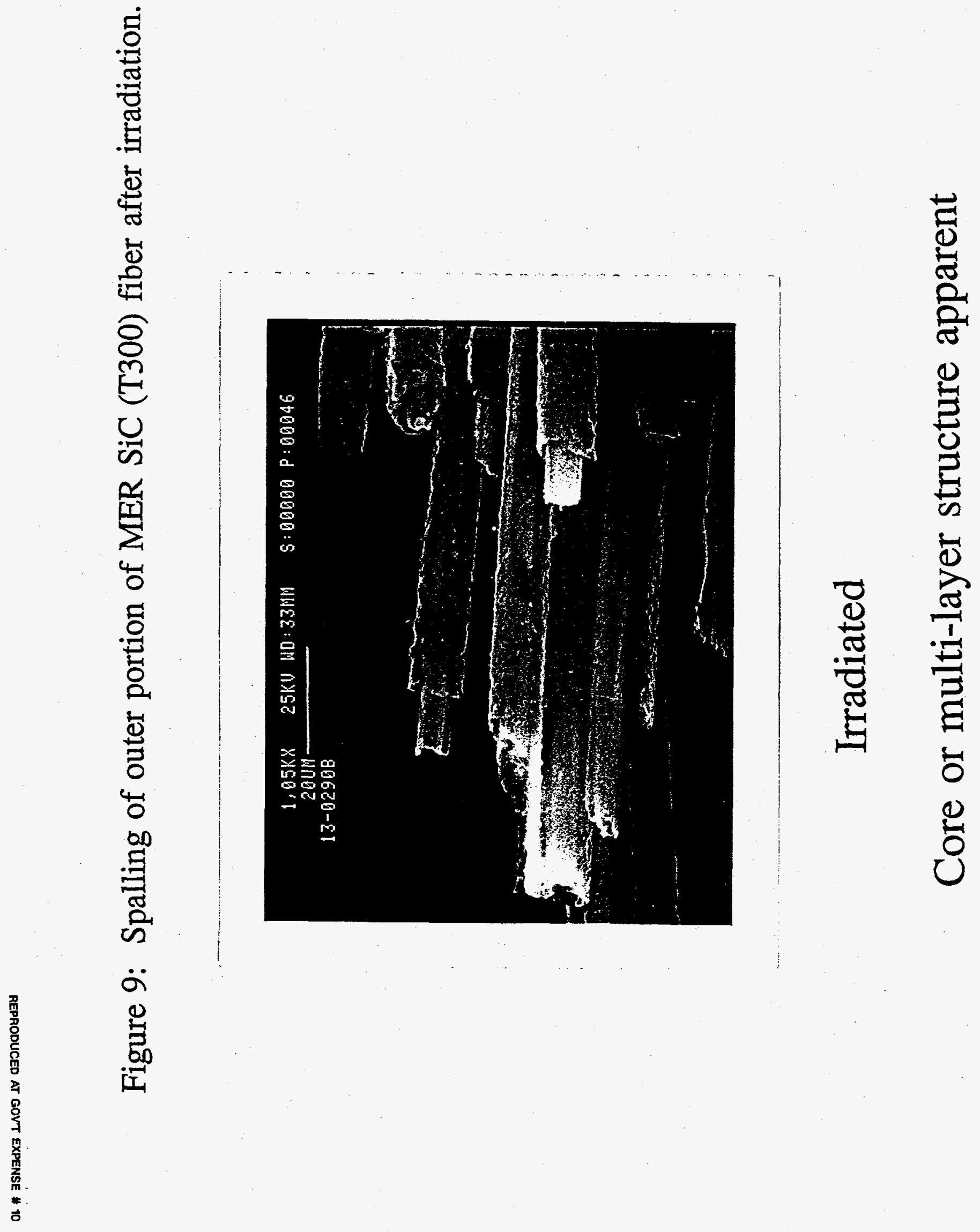


Figure 10: MER SiC (IM9) fiber before and after irradiation.
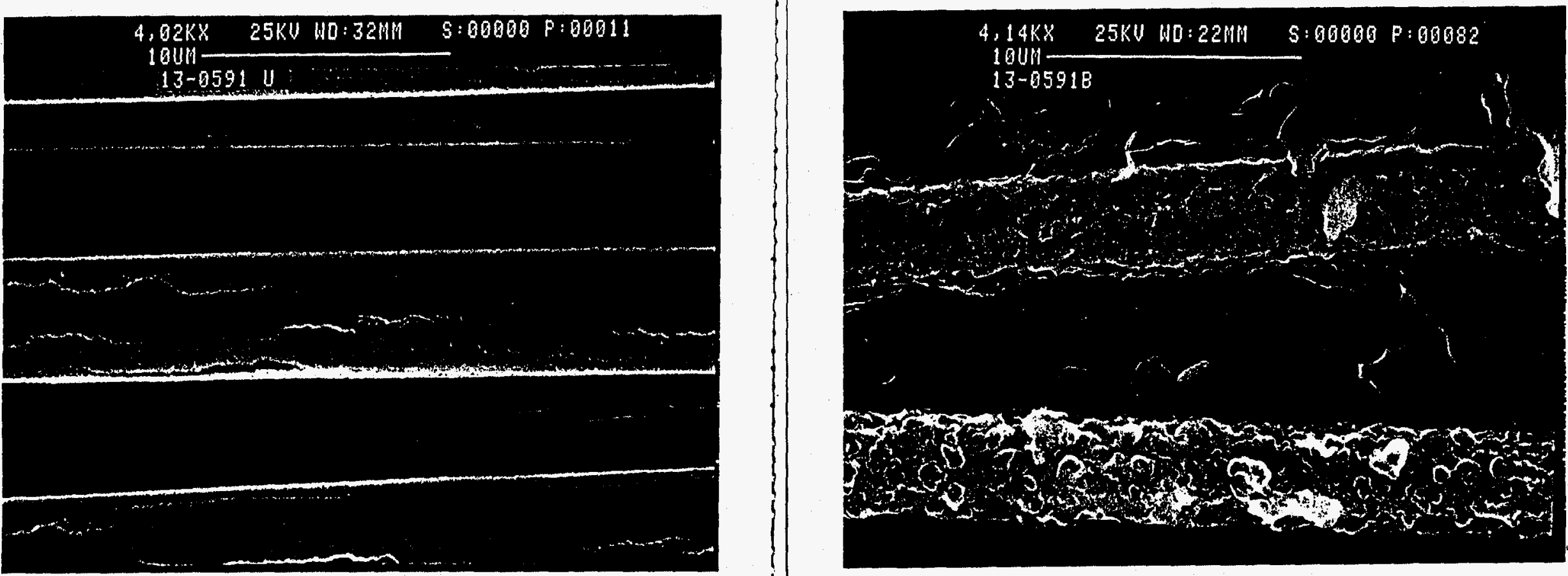

Unirradiated

Irradiated

Surface roughening, some fragmenting, crack healing? 
Figure 11: Textron SCS-6 fiber before and after irradiation.
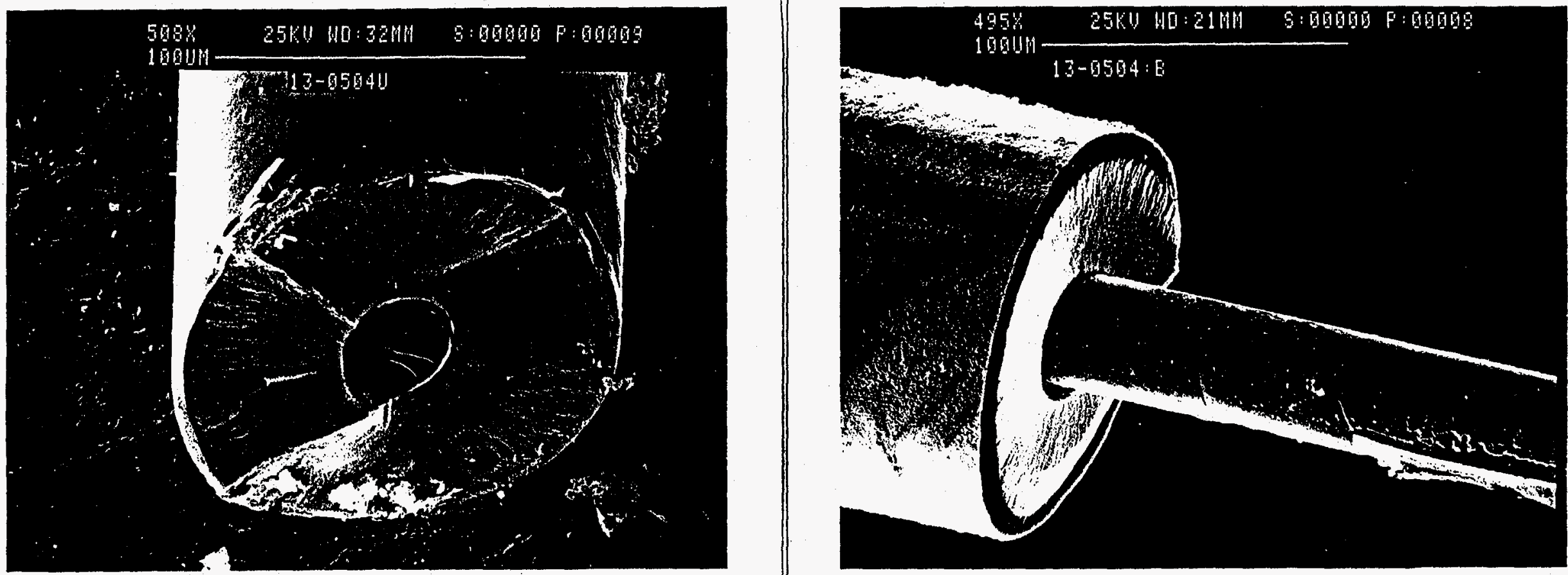

Unirradiated

Irradiated

Shrinkage of carbon core 


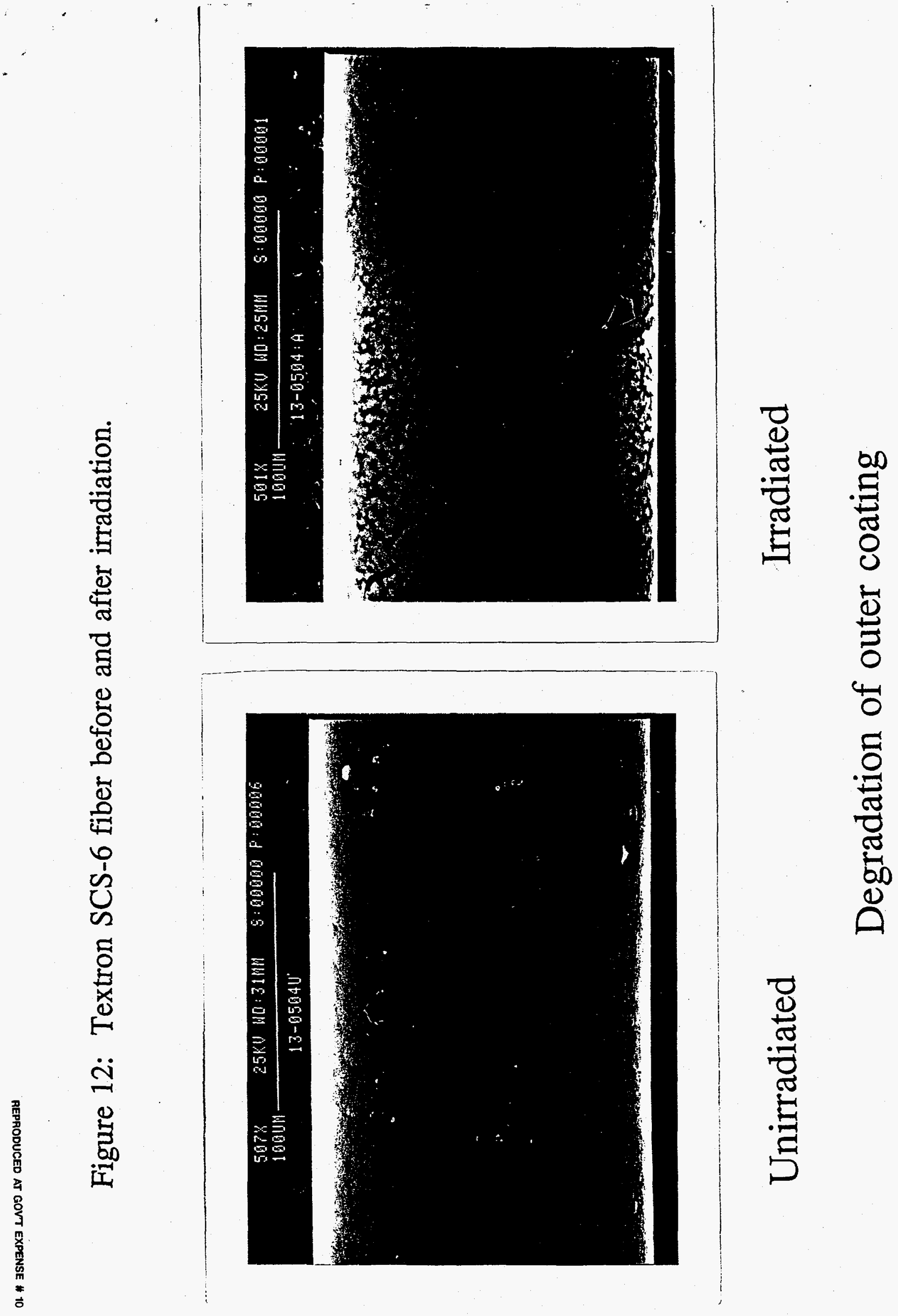

